\title{
Article
}

\section{Tetra Schiff Bases as Polyvinyl Chloride Thermal Stabilizers}

\author{
Dina S. Ahmed ${ }^{1}$, Mohammed Kadhom ${ }^{2}$, Angham G. Hadi ${ }^{3}{ }^{\circ}$, Muna Bufaroosha ${ }^{4}$, Nadia Salih ${ }^{5}(\mathbb{D}$, \\ Wedad H. Al-Dahhan ${ }^{6}$ and Emad Yousif ${ }^{6, *}$ (D)
}

1 Department of Medical Instrumentation Engineering, Al-Mansour University College, 10067 Baghdad, Iraq; dinasaadi86@gmail.com

2 Department of Environmental Science, College of Energy and Environmental Science, Alkarkh University of Science, 10081 Baghdad, Iraq; makbq6@mail.missouri.edu

3 Department of Chemistry, College of Science, Babylon University, 51002 Babil, Iraq; analhusainy@gmail.com

4 Department of Chemistry, College of Science, United Arab Emirates University, P.O. Box 15551, Al-Ain 1818, United Arab Emirates; muna.bufaroosha@uaeu.ac.ae

5 School of Chemical Sciences and Food Technology, Faculty of Science and Technology, Universiti Kebangsaan Malaysia, 43600 Bangi, Selangor, Malaysia; nadiaalnami@hotmail.com

6 Department of Chemistry, College of Science, Al-Nahrain University, 64021 Baghdad, Iraq; dahan6262@gmail.com

* Correspondence: emad_yousif@hotmail.com; Tel.: +964-770-583-9300

\section{check for}

updates

Citation: Ahmed, D.S.; Kadhom, M.; Hadi, A.G.; Bufaroosha, M.; Salih, N.; Al-Dahhan, W.H.; Yousif, E. Tetra Schiff Bases as Polyvinyl Chloride Thermal Stabilizers. Chemistry 2021, 3 , 288-295. https://doi.org/10.3390/ chemistry3010021

Received: 12 December 2020

Accepted: 14 February 2021

Published: 17 February 2021

Publisher's Note: MDPI stays neutral with regard to jurisdictional claims in published maps and institutional affiliations.

\begin{abstract}
Tetra Schiff bases were used as thermal stabilizers to enhance the properties of polyvinyl chloride (PVC) when operated at high temperatures. The thermal stability of PVC films doped with Schiff bases was tested by the weight-loss method, Fourier transform infrared (FTIR) spectroscopy, thermal aging test, optical microscope, and atomic force microscope (AFM). Results showed that embedding these additives increased the stability time of the polymer, which decreased the degradation reaction tendency. Furthermore, the primary color of PVC was improved by adding the Schiff bases using oven-aging. In addition, these Schiff bases resulted in a significant reduction in PVC's conjugated double bonds and, hence, the weight loss.
\end{abstract}

Keywords: polyvinyl chloride (PVC); Schiff bases; thermal stability; weight loss; thin films

\section{Introduction}

PVC (polyvinyl chloride) is one of the commonly applied thermoplastics used in a vast number of applications, such as plumbing supplies, construction parts, and healthcare equipment. Nevertheless, PVC experiences weak stability when exposes to high temperature and/or UV light, where these enhance the autocatalytic dehydrochlorination. In addition, the extracellular enzymes produced from microbes were found to act as breakers for the plasticizers and other components [1,2]. Different components were utilized as stabilizers by mixing them with PVC to hinder the degradation, decoloring, surface cracking, and mechanical lacking [3,4]. The stability additives commonly have two essential roles, namely, absorbing hydrogen chloride and substituting unstable chlorine atoms [5]. However, examples of traditional thermal stabilizers include lead salts [6], metal soaps [7], and organo-tin compounds [8]. The manufacturing of PVC parts and products includes filling different types of improvers, such as thermal stabilizers, plasticizers, and lubricants, where low compatibility happens due to the difference in properties among compounds.

Thereby, it became necessary to find single stabilizers with multidisciplinary functions in order to make the process less expensive and improve product quality. Here, Dong et al. prepared cis-1,2-cyclohexanedicarboxylic acid di-mannitol ester-based Zn alkoxides, which functioned as a plasticizer and thermal stabilizer for PVC [9]. In the same context, Li and co-workers found that mannitol stearate ester-based $\mathrm{Al}$ alkoxides (MSE-Al) are very active lubricants, plasticizers, and thermal stabilizers for PVC [10]. In this article, tetra Schiff bases were utilized as thermal stabilizers for PVC since these components improved 
the PVC's photostability in our previous work [11]. The effect of these compounds was investigated using different techniques. Results pointed out that PVC with tetra Schiff bases exhibited excellent long-term thermal stability.

\section{Materials and Methods}

\subsection{Synthesis of Tetra Schiff Bases 1-3}

PVC $($ K-value $=67$ and degree of polymerization $=800)$ was purchased from Petkim Petrokimya (Istanbul, Turkey). Schiff bases, numbered 1-3, were prepared by following procedure from the literature and used as PVC photo-stabilizers [11] and thermal-stabilizers. Biphenyl-3,3',4,4'-tetraamine was condensate with four mole equivalents aromatic aldehydes, namely 2-, 3-hydroxybenzaldehyde, and 4-nitrobenzaldehyde. The synthesis process was conducted in ethanol, catalyzed with acetic acid, and maintained under reflux for $4 \mathrm{~h}$. Figure 1 shows the structure of the prepared 1-3 Schiff bases. More details regarding these components' characterizations and properties were described in our previous work [11].<smiles>Oc1ccccc1/C=N/c1ccc(-c2ccc(/N=C/c3ccccc3O)c(/N=C/c3ccccc3O)c2)cc1/N=C/c1ccccc1O</smiles>

1<smiles>Oc1cccc(/C=N/c2ccc(-c3ccc(/N=C/c4cccc(O)c4)c(/N=C/c4cccc(O)c4)c3)cc2/N=C/c2cccc(O)c2)c1</smiles>

2<smiles>O=[N+]([O-])c1ccc(C=Nc2cc(-c3ccc(/N=C/c4ccc([N+](=O)[O-])cc4)c(/N=C/c4ccc([N+](=O)[O-])cc4)c3)ccc2/N=C/c2ccc([N+](=O)[O-])cc2)cc1</smiles>

3

Figure 1. Tetra Schiff bases 1-3.

\subsection{Preparation of PVC Films}

Five grams of PVC was dissolved in $100 \mathrm{~mL}$ of tetrahydrofuran and stirred for $30 \mathrm{~min}$ at ambient temperature. Then, $0.5 \mathrm{wt} . \%$ of the tetra Schiff bases were added separately to the PVC solution. The whole mixture was left to stir for $30 \mathrm{~min}$ at ambient temperature. Later, the final solution was cast on a piece of glass; the casted solution was left for one day at room temperature for solvent evaporation. Finally, the PVC films with about $40 \mu \mathrm{m}$ thickness were obtained directly after evaporation and used for further characterizations. It is good mentioning that the three prepared tetra Schiff bases were found to be completely miscible with PVC.

\subsection{Thermal Stability Test of PVC Films}

\subsubsection{Thermal Aging Test}

The color change was used to evaluate the thermal stability of PVC films, where they were placed in the oven at $180{ }^{\circ} \mathrm{C}$ and checked periodically every $20 \mathrm{~min}$. The attenuated total reflection-Fourier transform infrared (ATR-FTIR) device is Nicolet 4700 system purchased from Thermo Electron Corporation, which contains multi-reflection smart performers. However, the examination setups were collecting spectra from 500 to $4000 \mathrm{~cm}^{-1}$, scanning rate $=64$, and resolution $=2.0 \mathrm{~cm}^{-1}$. 


\subsubsection{Congo Red Test}

To measure the thermal stability of a polymer, the Congo Red test was conducted [12]. In this work, $2.5 \mathrm{~g}$ of PVC films were heated at $180^{\circ} \mathrm{C}$ in air presence; the samples were placed in test tubes that have $2.0 \mathrm{~cm}$ Congo Red test papers above the samples. The estimated time to observe the color change from red to blue was assigned as the thermal stability (Ts) time.

\section{Results and Discussion}

\subsection{Synthesis of the Tetra Schiff Bases}

The prepared tetra Schiff bases illustrated in Figure 1 were synthesized as previously reported [11]. The structure of Schiff bases 1-3 was confirmed by various spectral and analytical data and consistent with other works' findings.

\subsection{The FTIR Results of PVC Films}

In regard to studying the interaction and change that occurred between PVC chains and thermal stabilizers, FTIR spectra of PVC were investigated to detect the characteristic bands. PVC films showed bands around 1722 and $688 \mathrm{~cm}^{-1}$, which were assigned to $C=O$ and $\mathrm{C}-\mathrm{H}$ groups, respectively [13]. The intensities of the $\mathrm{C}=\mathrm{O}$ peak vibration was compared to a reference peak $\left(1328 \mathrm{~cm}^{-1}, \mathrm{C}-\mathrm{H}\right.$ bond vibrations). The FT-IR spectra reflected from blank PVC specimens during oven aging are shown in Figure 2. From the figure, the peak at $1722 \mathrm{~cm}^{-1}$ resulted from $\mathrm{C}=\mathrm{O}$ (carbonyl) moiety vibrations. This peak's intensity increased during oven aging, where the highest value was obtained after $120 \mathrm{~min}$.

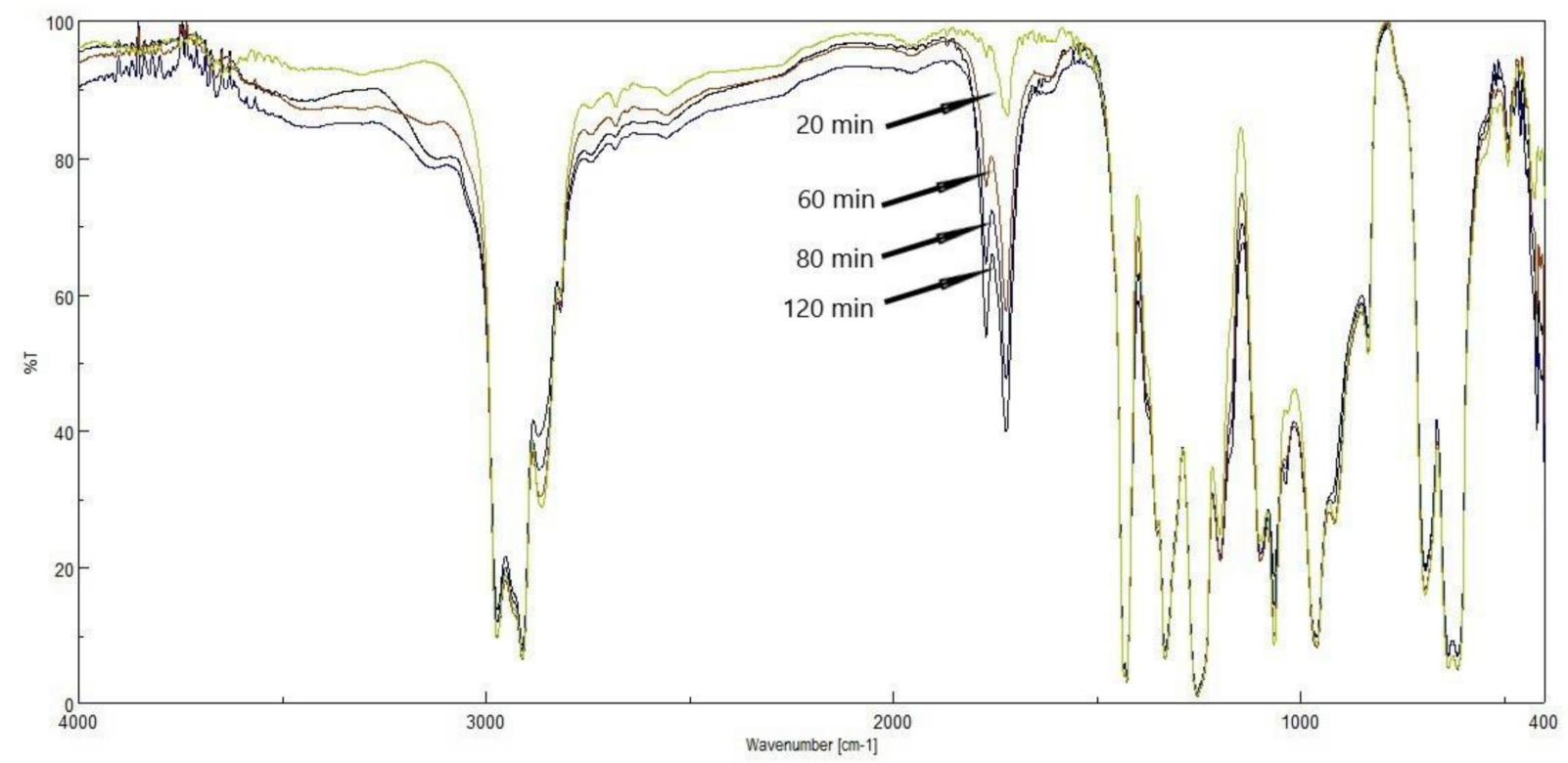

Figure 2. Attenuated total reflection-Fourier transform infrared (ATR-FT-IR) spectra of blank polyvinyl chloride (PVC) film during thermal degradation.

The functional group index (Is) is dependent on both the absorbance peak during the study $(A s)$ and that of the reference peak $(A r)$ using Equation (1) below [14].

$$
I s=A s / A r
$$

The carbonyl index $\left(I_{\mathrm{C}=\mathrm{O}}\right)$ of PVC films were calculated at different degradation times and presented in Figure 3. The degradation and change in the functional group index of each PVC film were carried out once only. Greater changes in the functional index values were observed for the blank PVC film compared to those of Schiff bases (1-3) films. These results confirm that the Schiff bases act as efficient PVC thermal stabilizers, where the lowest change in carbonyl index was achieved when Schiff base $\mathbf{1}$ (ortho-geometry) was 
added. Figure 3 shows the reduction in PVC's degradation when additives were present in comparison to the blank film.

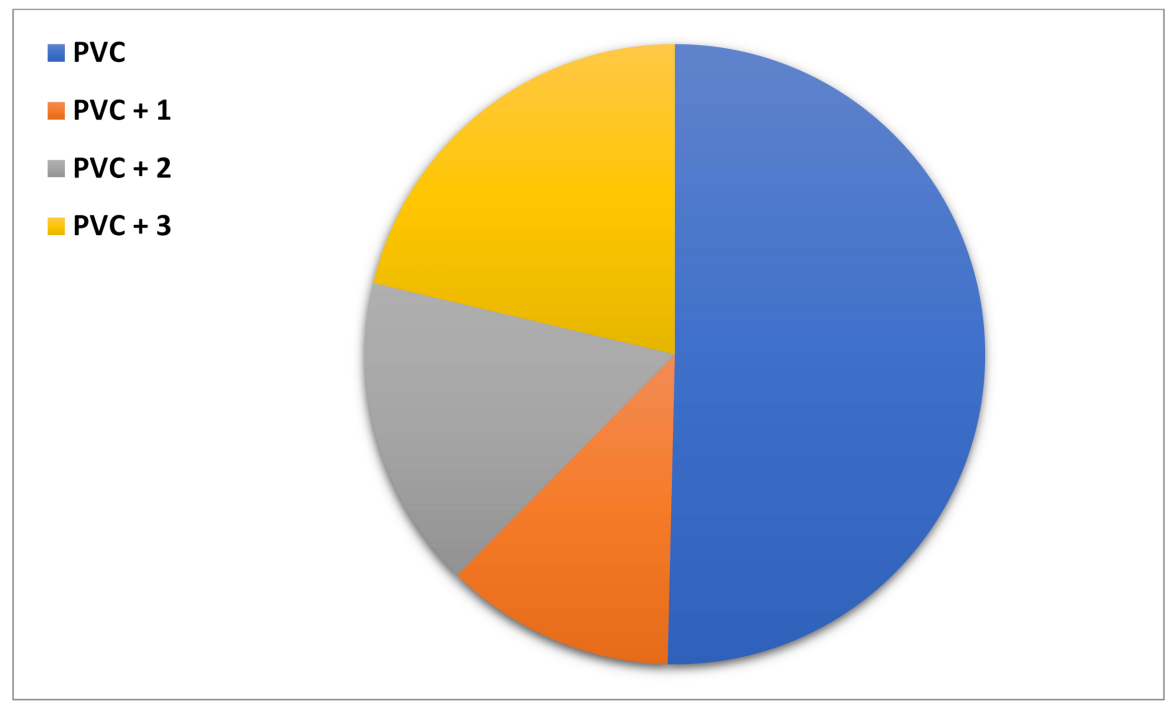

Figure 3. Changes in the $I_{\mathrm{C}=\mathrm{O}}$ upon thermal degradation.

\subsection{Mass Loss}

The dehydrochlorination of PVC polymer occurs at high temperatures and leads to a loss in the polymeric material due to the elimination of hydrogen chloride [15]. Such a process also leads to the evolution of volatile toxic pollutants and discoloration of the polymeric material. The use of Schiff bases 1-3 can stabilize the PVC against oven-aging degradation. PVC films were heated for a while, and the weight loss (\%) was calculated every 20 min using Equation (1) [16], wherein $W_{o}$ is the film's weight before heating and $W_{t}$ is the weight at an appropriate time point.

$$
\text { Weight loss }(\%)=\left[\left(W_{0}-W_{t}\right) / W_{0}\right] \times 100
$$

The changes in weight loss (\%) of PVC films at multiple degradation time points are shown in Figure 4. However, the weight loss for PVC (blank) film was higher than those obtained from films doped with Schiff bases. The lowest loss in weight was demonstrated by the PVC film with Schiff base $\mathbf{1}$.

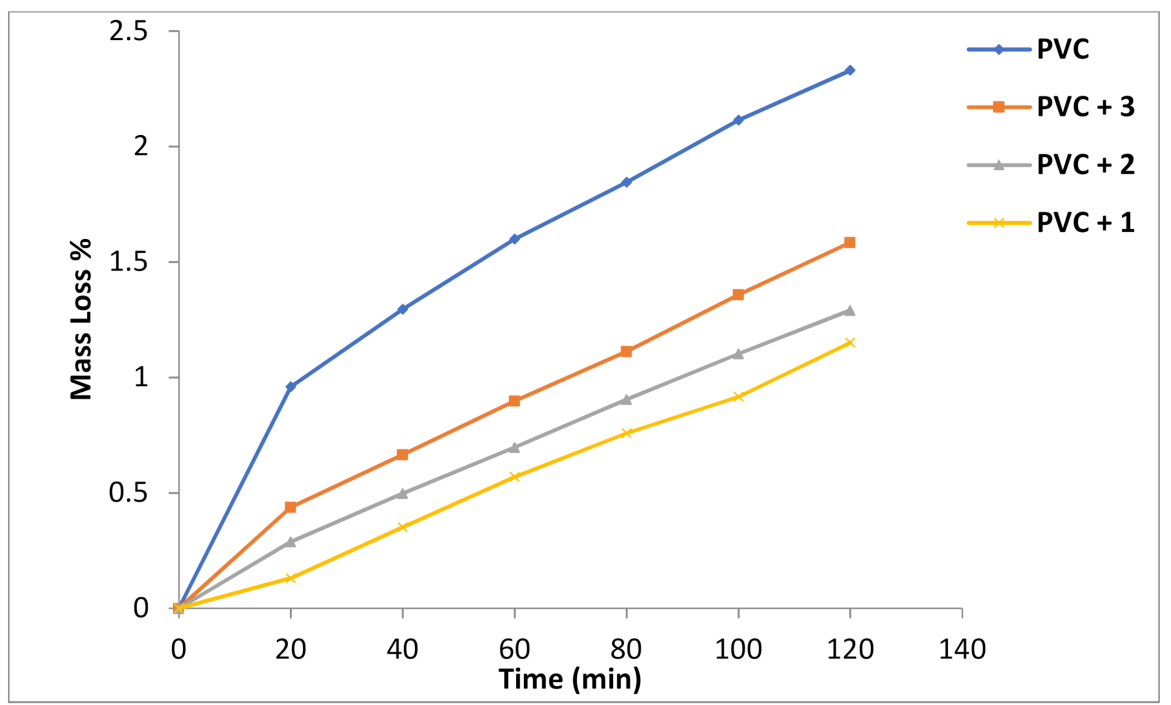

Figure 4. Changes in mass loss (\%) upon thermal degradation. 


\subsection{Congo Red Test}

Figure 5 illustrates the outcomes of Congo Red test, where the acidic compounds, mainly hydrogen chloride, were measured at $180^{\circ} \mathrm{C}$. The stability time (Ts) of PVC (blank) was around $20 \mathrm{~min}$. However, filling the thermal stabilizers resulted in a significant increase, and differ from an additive to another. Here, the stability time of PVC films containing Schiff bases were 35, 41, and 52 min by embedding Schiff bases 3, 2, and 1, respectively. These findings were attributed to the interaction between the Schiff bases and PVC chains. The Ts of PVC with Schiff base 1 reached 52 min, indicating that Schiff base 1 has the highest impact in inhibiting PVC's degradation.

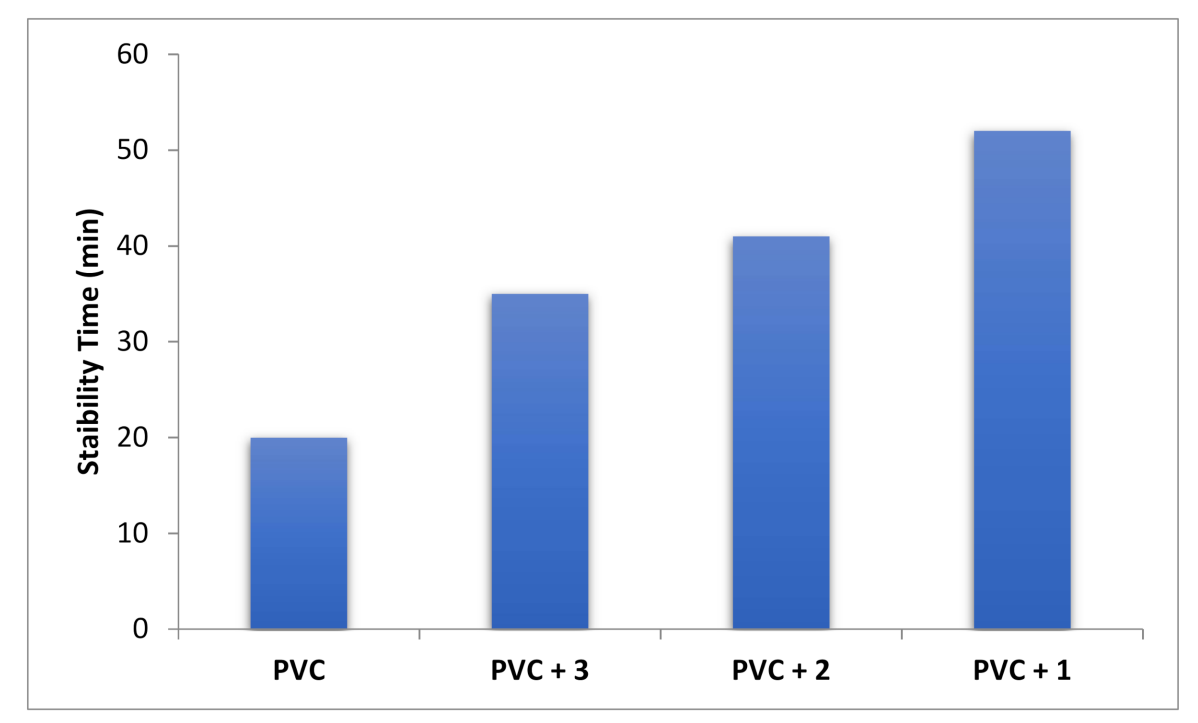

Figure 5. The stability time of PVC films.

\subsection{Oven-Aging Test}

Oven aging for PVC samples was used to test color stability by optical microscopy, as listed in Table 1. From the table, the aging process phenomenon took place at different rates depending on the film's structure. Hence, film colors changed due to the dehydrochlorination and generation of conjugated double bonds in the PVC samples. However, the blank PVC changed quickly during the aging process and turned black within $20 \mathrm{~min}$. PVC films containing Schiff bases enhanced the thermal and color stability and showed higher resistance to coloration. PVC films with Schiff bases $\mathbf{3}$ and $\mathbf{2}$ turned black when heated for 40 and $60 \mathrm{~min}$, respectively. The best thermal stability was obtained for the PVC sheet containing Schiff base 1, where the blackening occurred after $120 \mathrm{~min}$. Furthermore, the original color of the PVC film embedded with Schiff base $\mathbf{1}$ after heating was lighter and better than others (Table 1).

\subsection{Mechanism of Improving PVC's Thermal Stability by Additives (Scale of $100 \mu \mathrm{m}$ )}

The color of PVC films turned darker due to the formation of unstable compounds of tert-Butyl chloride and allyl chloride as presented in Scheme 1. Thus, releasing hydrochloride molecules became facile and enhanced the formation of the double bonds, which increased the conjugation system and made the polymer darker.

Investigating the effect of adding stabilizers within the PVC's structure is crucial due to the industrial applications of this polymer that requires high stabilization efficiency and discoloration resistance. The stabilizers' concentration was kept at $0.5 \mathrm{wt} . \%$, where higher amounts lead to a change in the properties of the polymer. Generally, the thermal stabilizer works by the displacement mechanism of active or labile substituent groups, such as the chlorine atom attached to tertiary carbon or in a-position to a tertiary carbon, and the allylic chlorine. However, a different mechanism could be assumed; these additives could block 
the odd electron sites created on the PVC chain and disrupting the radical chain, as shown in Scheme 2.

Table 1. Color evolutions of PVC films heated at $180^{\circ} \mathrm{C}$.

\begin{tabular}{|c|c|c|c|c|c|c|c|}
\hline \multirow{2}{*}{ Film } & \multicolumn{7}{|c|}{ Degradation Time (min) } \\
\hline & 0 & 20 & 40 & 60 & 80 & 100 & 120 \\
\hline PVC & & & & & & & \\
\hline $\mathrm{PVC}+3$ & & & & & & & \\
\hline $\mathrm{PVC}+2$ & & & & & & & \\
\hline $\mathrm{PVC}+1$ & & & & & & & \\
\hline
\end{tabular}<smiles>CCC(Cl)(CC)CC</smiles>

a

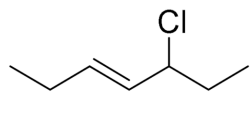

b

Scheme 1. Chemical structures of (a) tert-butyl chloride (b) allyl chloride.

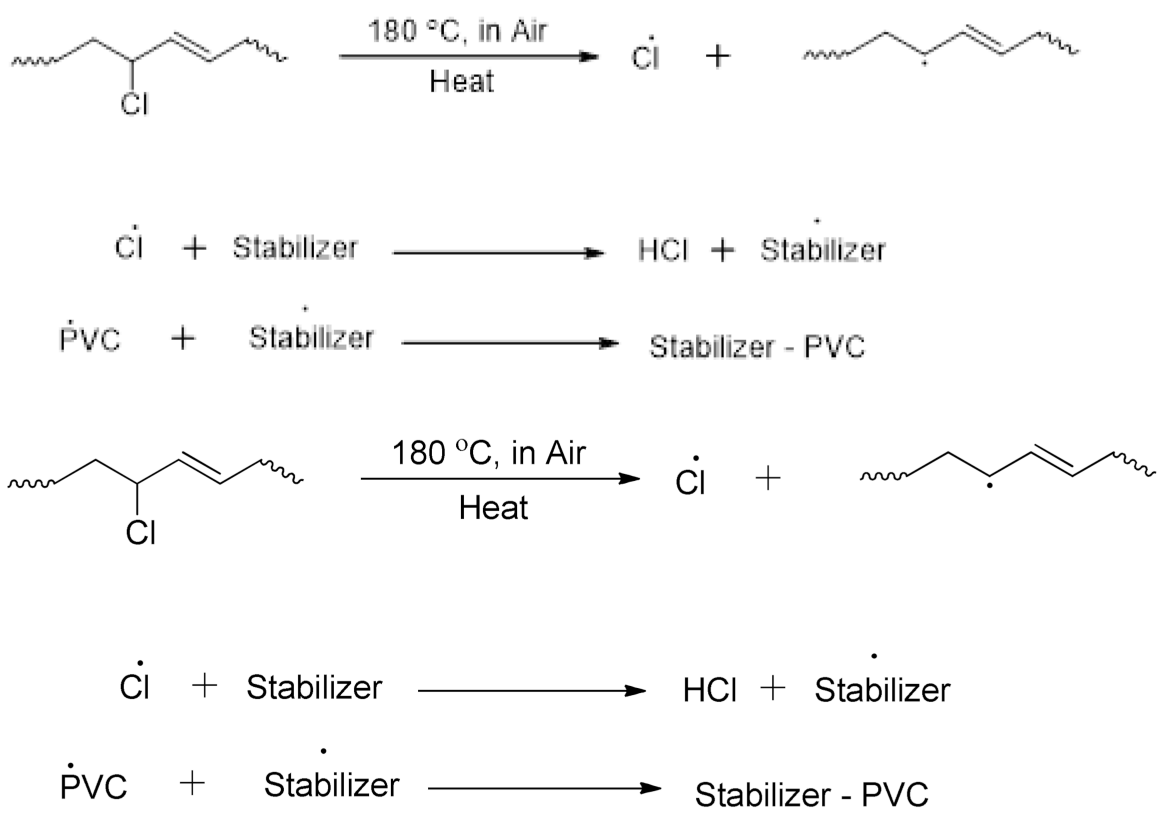

Scheme 2. General free radical mechanism of the investigated stabilizers during the thermal stabilization test of PVC. 


\subsection{Atomic Force Microscope (AFM)}

Various reports suggest that AFM can be used to investigate the irregular and rough polymer surface of materials exposed to irradiation [17]. PVC films were heated up to $180^{\circ} \mathrm{C}$ for $120 \mathrm{~min}$, after which, 2D and 3D AFM images of the surface were captured. Figures 6 and 7 show AFM images for PVC (blank) and PVC containing Schiff base 1, respectively. Both figures identified a relatively regular packaging of lamellar crystals that have different sizes and shapes. Clearly, Schiff base $\mathbf{1}$ has the greatest thermostabilizing effect and improved the roughness factor by more than ninefold compared to the blank PVC film (Figure 6). This outcome shows that the rates of dehydrochlorination and bondbreaking have noticeably reduced with the presence of Schiff base $\mathbf{1}$ [17].
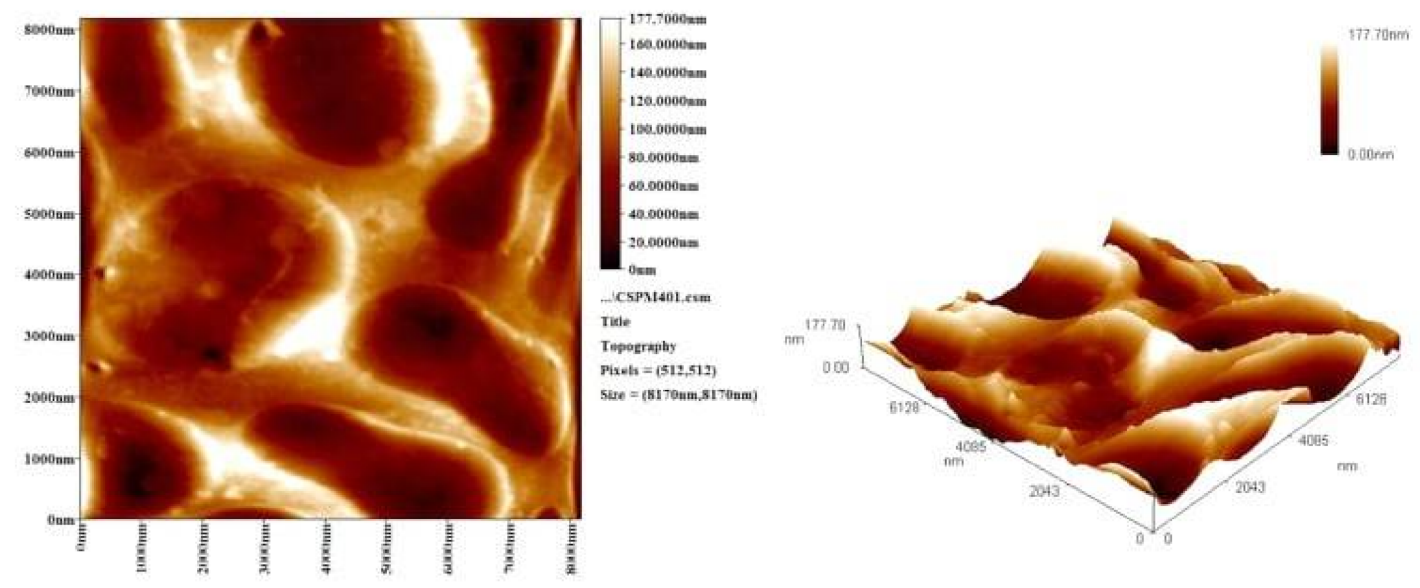

Figure 6. Atomic force microscopy (AFM) images of PVC (blank) film after 120 min of thermal degradation at $180{ }^{\circ} \mathrm{C}$.
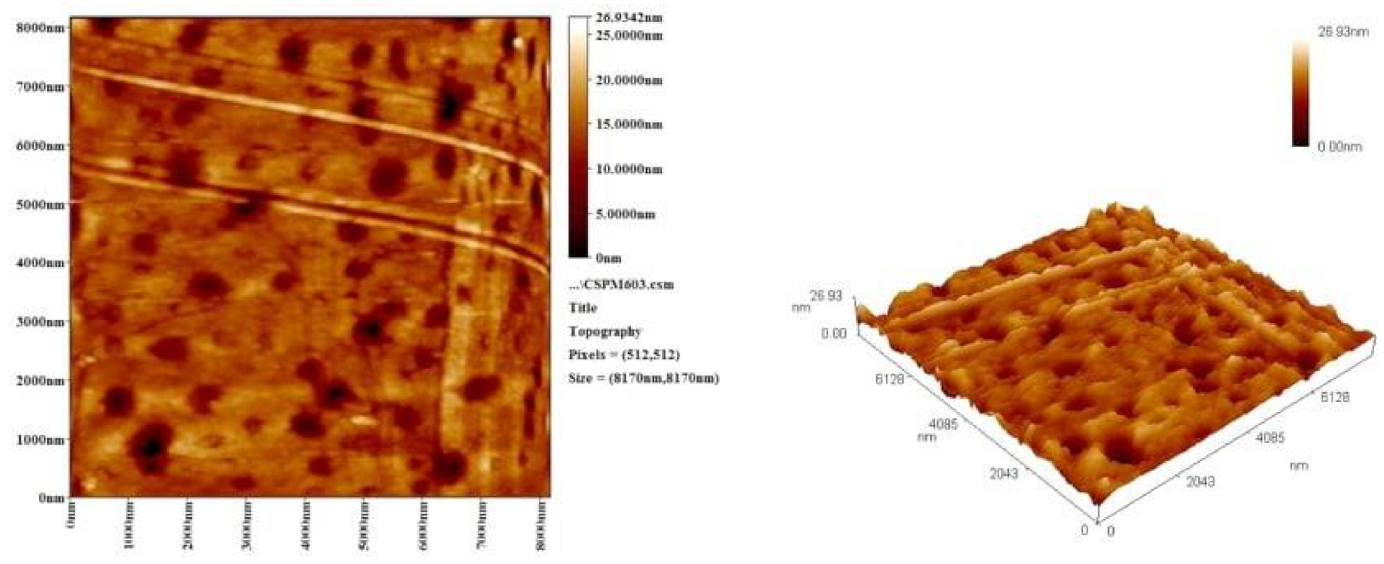

Figure 7. AFM images of PVC containing Schiff base $\mathbf{1}$ film after $120 \mathrm{~min}$ of thermal degradation at $180{ }^{\circ} \mathrm{C}$.

\section{Conclusions}

PVC films were doped with three in situ prepared Schiff bases in order to enhance the thermal stability of the polymer and prevent degradation. By conducting the oven-aging test, an improvement was observed for the initial color and onset of blackening time of PVC films. Characterization methods of growing certain functional groups in the infrared spectra, weight loss, and monitoring the morphology by an optical microscope and atomic force microscopy were used to determine the impact of Schiff bases. Findings demonstrated that color change took longer, and the blackening time was delayed to $120 \mathrm{~min}$. In general, PVC with Schiff bases showed a remarkable improvement in thermal stability, which was attributed to the high $\mathrm{HCl}$ neutralization ability and labile chlorine atoms passivation within the polymer chains. 
Author Contributions: D.S.A. conducted the experimental section and wrote the first draft; M.K. revised the writing; A.G.H. analyzed the data; M.B. and N.S. reviewed the work; W.H.A.-D. collected and revised the data; E.Y. supervised the team. All authors have read and agreed to the published version of the manuscript.

Funding: This work received no funding.

Data Availability Statement: Not applicable.

Acknowledgments: Authors like to thank their affiliations for partially supporting this work.

Conflicts of Interest: The authors declare no conflict of interest.

\section{References}

1. Yu, J.; Sun, L.; Ma, C.; Qiao, Y.; Yao, H. Thermal degradation of PVC: A review. Waste Manag. 2016, 48, 300-314. [CrossRef]

2. Correa, C.A.; de Santi, C.R.; Leclerc, A. Green-PVC with full recycled industrial waste and renewably sourced content. J. Clean. Prod. 2019, 229, 1397-1411. [CrossRef]

3. Starnes, W.H. Structural Defects in Poly(vinyl chloride). J. Polym. Sci. Pol. Chem. 2005, 43, 2451-2467. [CrossRef]

4. Arslan, M.; Acik, G.; Tasdelen, M.A. The emerging applications of click chemistry reactions in the modification of industrial polymers. Polym. Chem. 2019, 10, 3806-3821. [CrossRef]

5. Ark1s, E.; Balköse, D. Thermal stabilization of poly(vinyl chloride) by organotin compounds. Polym. Degrad. Stab. 2005, 88, 46-51. [CrossRef]

6. Kalouskova, R.; Novotna, M.; Vymazal, Z. Investigation of thermal stabilization of poly(vinyl chloride) by lead stearate and its combination with synthetic hy- drotalcite. Polym. Degrad. Stab. 2004, 85, 903-909. [CrossRef]

7. Wang, M.; Xu, J.; Wu, H.; Guo, S. Effect of pentaerythritol and organic tin with calcium/zinc stearates on the stabilization of poly(vinyl chloride). Polym. Degrad. Stab. 2006, 91, 2101-2109. [CrossRef]

8. Wang, M.; Song, X.; Jiang, J.; Xia, J.; Li, S.; Li, M. Excellent hydroxyl and nitro- gen rich groups-containing tung-oil-based Ca/Zn and polyol stabilizers for enhanced thermal stability of PVC. Thermochim. Acta 2017, 658, 84-92. [CrossRef]

9. Dong, T.; Li, D.; Li, Y.; Han, W.; Zhang, L.; Xie, G.; Sunarso, J.; Liu, S. Design and synthesis of polyol ester-based zinc metal alkoxides as a bi-functional thermal stabilizer for poly(vinyl chloride). Polym. Degrad. Stab. 2019, 159, 125-132. [CrossRef]

10. Han, W.; Zhang, M.; Li, D.; Dong, T.; Ai, B.; Dou, J.; Sun, H. Design and Synthesis of a New Mannitol Stearate Ester-Based Aluminum Alkoxide as a Novel Tri-Functional Additive for Poly(Vinyl Chloride) and Its Synergistic Effect with Zinc Stearate. Polymers 2019, 11, 1031. [CrossRef] [PubMed]

11. Ahmed, D.S.; El-Hiti, G.A.; Hameed, A.S.; Yousif, E.; Ahmed, A. New Tetra-Schiff Bases as Efficient Photostabilizers for Poly(vinyl chloride). Molecules 2017, 22, 1506. [CrossRef] [PubMed]

12. Li, M.; Zhang, J.; Huang, K.; Li, S.; Jianga, J.; Xia, J. Mixed calcium and zinc salts of dicarboxylic acids derived from rosin and dipentene: Preparation and thermal stabilization for PVC. RSC Adv. 2014, 4, 63576-63585. [CrossRef]

13. Coltro, L.; Pitta, J.B.; Madaleno, E. Performance evaluation of new plasticizers for stretch PVC films. Polym. Test. 2013, 32, 272-278. [CrossRef]

14. El-Hiti, G.A.; Ahmed, D.S.; Yousif, E.; Alotaibi, M.H.; Satar, H.A.; Ahmed, A.A. Influence of Polyphosphates on the Physicochemical Properties of Poly (Vinyl Chloride) after Irradiation with Ultraviolet Light. Polymers 2020, 12, 193. [CrossRef] [PubMed]

15. Sabaa, M.W.; Oraby, E.H.; Naby, A.S.A.; Mohamed, R.R. N-Phenyl-3-substituted-5-pyrazolone derivatives as organic stabilizer for rigid PVC against photodegradation. J. Appl. Polym. Sci. 2005, 101, 1543-1555. [CrossRef]

16. Hadi, A.G.; Yousif, E.; El-Hiti, G.A.; Ahmed, D.S.; Jawad, K.; Alotaibi, M.H.; Hashim, H. Long-Term Effect of Ultraviolet Irradiation on Poly(vinyl chloride) Films Containing Naproxen Diorganotin(IV) Complexes. Molecules 2019, 24, 2396. [CrossRef] [PubMed]

17. El-Hiti, G.A.; Alotaibi, M.H.; Ahmed, A.A.; Hamad, B.A.; Ahmed, D.S.; Ahmed, A.; Hashim, H.; Yousif, E. The morphology and performance of polyvinyl chloride containing melamine Schiff bases against ultraviolet light. Molecules 2019, 24, 803. [CrossRef] [PubMed] 